\title{
Desenvolvimento de Heliconia psittacorum e Gladiolus hortulanus irrigados com águas residuárias tratadas ${ }^{1}$
}

\author{
Lousane L. Cerqueira ${ }^{2}$, Francisco de S. Fadigas ${ }^{2}$, Francisco A. Pereira ${ }^{2}$, Thomas V. Gloaguen ${ }^{2}$ \& João A. Costa ${ }^{2}$
}

\begin{abstract}
RESUMO
O objetivo primordial com este trabalho é avaliar o impacto do uso de águas residuárias domésticas tratadas (ART) no desenvolvimento de espécies ornamentais, razão por que se instalou o ensaio no município de Simões Filho, BA, em delineamento experimental de blocos casualizados, com parcelas subdivididas, cultivadas com Heliconia psittacorum e Gladiolus hortulanus e irrigadas por gotejamento com ART e com água de riacho; avaliaram-se o comprimento das hastes, número de botões florais (helicônia e gladíolo), altura das plantas, número de perfilhos, diâmetro da touceira e nutrientes (somente helicônia). Dentre os fatores que afetam o desenvolvimento das plantas, avaliaram-se a porosidade e a salinidade (condutividade elétrica - CE) do solo, de 0 a 0,3 m. Não se observaram diferenças significativas no desenvolvimento das plantas; ressalta-se que micro e macroporosidade, CE e sodicidade, também não indicaram diferenças entre os tratamentos depois de 180 dias de irrigação, mas se observou início de salinização do solo após 1 ano de experimento, o que significa possíveis alterações dos parâmetros avaliados a médio e longo prazos.
\end{abstract}

Palavras-chave: reúso de água, helicônia, gladíolo, salinidade do solo, porosidade do solo

\section{Growth of Heliconia psittacorum and Gladiolus hortulanus irrigated with treated domestic wastewater}

\begin{abstract}
This research aims to evaluate the impact of irrigation with treated domestic wastewater (TDW) on the growth of ornamental plant species. The experiment was installed in the town of Simões Filhos (BA), in a randomized block design with subdivided plots, cultivated with Heliconia psittacorum and Gladiolus hortulanus using surface drip irrigation with TDW and river water. The evaluated parameters were: stem length, button number (parakeet flower and gladiola), and plant height, number of tillers, plant diameter and nutriment content (only parakeet flower). Among the factors which affect the growth of the plant, soil porosity and soil salinity (electrical conductivity - EC) were measured for 0 to $0.3 \mathrm{~m}$ soil depth. No significant difference was observed for the plant morphology. Changes in soil micro and macroporosity, EC and sodicity after 180 days of irrigation were also insignificant. However, a beginning of soil salinization was found after one year of experimentation, which signifies a possible change in the monitored parameters in the medium to long term.
\end{abstract}

Key words: water reuse, parakeet flower, gladiola, soil salinity, soil porosity

Parte da Dissertação de Mestrado do primeiro autor

${ }^{2}$ CCAAB/UFRB. CEP 44380-000, Cruz das Almas BA. Fone: (75) 3621-9359/5540. E-mails: lousanelordelo@hotmail.com; fadigas@ufrb.edu.br; pereiras@ufrb.edu.br; tgloaguen@gmail.com; albany@ufrb.edu.br 


\section{INTRODUÇÃO}

Em virtude da pressão demográfica e econômica da sociedade moderna, a oferta de recursos hídricos tem diminuído em quantidade e qualidade (Trentin, 2005); ante este panorama, Folegatti et al. (2005) salientam a necessidade de se buscar uma forma de se utilizar este recurso natural com maior racionalidade, por meio de técnicas que promovam um aproveitamento mais eficiente da água, em diversas atividades humanas.

Para Telles (2003), as águas de qualidade inferior, como as águas residuárias, particularmente as domésticas devem, sempre que possível, ser consideradas fontes alternativas para usos menos restritivos, como a agricultura, onde água de padrões baixos de qualidade pode ser usada para a irrigação; neste sentido, Hespanhol (2003), chama a atenção para a necessidade do uso de tecnologias apropriadas na eficiência do uso e no controle da demanda dessas fontes, como estratégia básica para a solução do problema da falta universal de água; assim, uma nova tática de consumo se está desenvolvendo em todo o mundo visando conservar a sua disponibilidade e qualidade: “o reúso de água”.

Aproximadamente 500.000 ha de terras agrícolas, em cerca de 15 países, estão sendo irrigados com águas residuárias domésticas, entre eles Israel detêm um dos mais ambiciosos programas de reutilização de águas, sendo que 70\% das águas residuárias do País são reutilizadas para a irrigação de 19.000 ha (Folegatti et al., 2005). O reúso planejado dessas águas na agricultura vem sendo apontado como forte medida para atenuar o problema da escassez hídrica no semiárido (Sousa \& Leite, 2003).

O reúso de água é uma alternativa que se vem mostrando viável e vários são os benefícios provenientes de sua aplicação na agricultura; entre as vantagens do reúso, mencionamse: a possibilidade de substituição parcial de fertilizantes químicos, com diminuição do impacto ambiental, em função da redução da contaminação dos cursos d'água; as plantas podem ser beneficiadas não apenas pela água mas, também, dentro de certos limites, pelos materiais dissolvidos no esgoto doméstico (como matéria orgânica, nitrogênio, fósforo, potássio e micronutrientes) além da economia da quantidade de água direcionada em grandes volumes para a irrigação, que representa a maior demanda de água nas regiões secas (Pescod, 1992; Bernardi, 2003).

Quando aplicado no solo, o esgoto bruto ou tratado sofre autodepuração, através de processos físicos, químicos e biológicos, que reduzem sua carga poluidora (Gloaguen et al., 2007); por outro lado, a aplicação de águas residuárias no solo pode apresentar diversos efeitos negativos. Na ausência de lixiviação e na presença de evapotranspiração excessiva, a irrigação promova o acúmulo de sais na zona radicular (Bernstein, 1974), o que pode comprometer o desenvolvimento das plantas; a situação se agrava na medida em que o solo seca, pois as plantas passam a sofrer, tanto pelo estresse matricial quanto pelo estresse osmótico (Rhoades et al., 2000; Gloaguen, 2006); além disso, a água residuária possui, em geral, altos valores de Razão de Adsorção de Sódio (RAS), elevando a Percentagem de Sódio Trocável (PST) dos solos irrigados, o que pode provocar redução da condutividade hidráulica e drenagem (Gonçalves et al., 2007).

Azevedo \& Oliveira (2005), ressaltam a importância da utilização de águas residuárias domésticas para o fornecimento de nutrientes e aumento de produtividade. Ao aplicarem esgoto residencial tratado por gotejamento em cultura de pepino (Cucumis sativus L.), obtiveram um aumento de 40,7\% na produção. Papadopolous \& Stylianou (1991), concluíram que o uso de água residuária proporcionou alto rendimento e boa qualidade em sementes de girassol, além de ter diminuído as quantidades de fertilizantes à base de nitrogênio e fósforo.

Através deste trabalho se objetivou avaliar o impacto da utilização de água residuária tratada em alguns componentes de produção de duas plantas ornamentais, Heliconia psittacorum (L.) cv. Golden torch e Gladiolus hortulanus (Bailey) e também a salinidade, sodicidade e porosidade do solo, suscetíveis de influenciar o desenvolvimento das culturas.

\section{MATERIAL E MÉTODOS}

A parte experimental do trabalho foi instalada no final de novembro de 2004, no município de Simões Filho, BA, localizado a uma altitude média de $50 \mathrm{~m}$, a $12^{\circ} 47^{\prime}$ de Latitude Sul e $38^{\circ} 23^{\prime}$ de Longitude Oeste, distanciando-se 22 km da capital do Estado; apresenta clima úmido (B1rA') na classificação de Thornthwaite, com temperaturas médias anuais de $24,7^{\circ} \mathrm{C}$, pluviosidade média anual entre 1600 e 2000 mm; as maiores concentrações pluviométricas ocorrem entre os meses de abril e junho. A área experimental se encontrava situada próxima ao condomínio residencial Crescer (Mapele - Centro Industrial de Aratu), onde é coletado, tratado e reutilizado todo o esgoto gerado pelo próprio condomínio. O solo da área experimental foi classificado como Cambissolo Háplico $\mathrm{T}_{\mathrm{B}}$ Distrófico típico.

O delineamento experimental foi em blocos casualizados com parcelas subdivididas. As espécies ornamentais utilizadas foram o híbrido Heliconia psittacorum (L.) cv. Golden torch e Gladiolus hortulanus (Bailey), dispostas em parcelas de $5 \times 15 \mathrm{~m}\left(75 \mathrm{~m}^{2}\right)$; o espaçamento foi de $1 \mathrm{~m}$ entre fileiras por $1 \mathrm{~m}$ entre plantas, para as helicônias e de 1 por 0,25 m para os gladíolos, utilizando-se cinco linhas por parcela, em que as três centrais representaram a parcela útil.

As plantas foram irrigadas por gotejamento em superfície e o sistema de irrigação distribuído em faixas, de acordo com o tipo de água utilizado. Os tratamentos aplicados nas parcelas, foram: T1 - água residuária tratada e desinfetada pela adição de $5 \mathrm{mg} \mathrm{L}^{-1}$ de cloro (AR c/ desinfecção); T2 água residuária tratada (AR s/ desinfecção) e T3 - água de riacho. A água residuária, proveniente de cerca de 50 casas do condomínio Crescer - Mapele, foi previamente tratada numa Estação de Tratamento da Esgoto composta de uma grade, um desarenador/equalizador, um Digestor Anaeróbico de Fluxo Ascendente (DAFA), uma wetland e uma caixa de passagem.

Realizou-se o preparo do solo com grade aradora, a profundidade de 0,20 m; em seguida, efetuou-se a distribuição 
do calcário (2900 kg ha-1 de calcário com PRNT 80\%) e mais uma gradagem, para incorporação do corretivo, enquanto a área experimental recebeu uma adubação de composto orgânico (à base de esterco de matadouro, cama de poedeira, bagaço de cana e farinha de rocha - $\mathrm{MB}_{4}$ ), aplicado nas covas de plantio, sendo $1 \mathrm{~L}$ por cova para helicônias e $0,5 \mathrm{~L}$ por cova para gladíolos.

Coletaram-se, com trado holandês, amostras deformadas de solo, em três profundidades (P1) 0-0,1 m; (P2) 0,1-0,2 m e (P3) 0,2-0,3 m, para determinação da granulometria e condutividade elétrica do solo (CE); as análises foram realizadas no Laboratório de Física do Solo da Escola de Agronomia da UFRB, utilizando-se, respectivamente, os métodos da pipeta e mesa de tensão, conforme recomendações da EMBRAPA (1997). A textura foi definida em triângulo de classificação textural, segundo Lemos \& Santos (1996). A Tabela 1 apresenta os resultados das análises granulométricas, de porosidade e a classificação da textura.

Tabela 1. Características físicas e físico-químicas do solo na área experimental

\begin{tabular}{|c|c|c|c|c|c|c|c|}
\hline \multirow{3}{*}{$\begin{array}{c}\text { Prof. } \\
\text { m }\end{array}$} & \multirow{2}{*}{ Areia } & \multirow{2}{*}{ Silte } & \multirow{2}{*}{ Argila } & \multicolumn{3}{|c|}{ Porosidade } & \multirow{3}{*}{$\begin{array}{c}\text { CE } \\
\mathrm{dS} \mathrm{m}^{-1}\end{array}$} \\
\hline & & & & total & macro & micro & \\
\hline & & $\mathrm{g} \mathrm{kg}^{-1}$ & & & $\mathrm{~m}^{3} \mathrm{~m}^{3}$ & & \\
\hline 0,1 & 85,7 & 440,5 & 472,5 & 41,5 & 4,8 & 36,7 & 0,342 \\
\hline 0,2 & 80,5 & 411,7 & 506,2 & 43,2 & 3,0 & 40,2 & 0,299 \\
\hline 0,3 & 73,7 & 360,0 & 565,2 & - & - & - & 0,239 \\
\hline
\end{tabular}

As amostras de solo de $0,0 \mathrm{~m}$ a $0,2 \mathrm{~m}$ foram analisadas no Laboratório de Solos da EBDA (Empresa Baiana de Desenvolvimento Agrícola) que apresentou as seguintes características químicas: $\mathrm{pH} \mathrm{H} \mathrm{H}_{2} \mathrm{O}=5,2 ; \mathrm{C}=5,25 \mathrm{~g} \mathrm{~kg}^{-1}$; $\mathrm{MO}=$ 9,05 $\mathrm{g} \mathrm{kg}^{-1} ; \mathrm{P} \leq 1 \mathrm{mg} \mathrm{dm}{ }^{-3} ; \mathrm{K}=0,09 \mathrm{cmol}_{\mathrm{C}} \mathrm{dm}^{-3} ; \mathrm{Ca}^{2+}=$ $1,31 \mathrm{cmol}_{\mathrm{C}} \mathrm{dm}^{-3} ; \quad \mathrm{Mg}^{2+}=1,94 \mathrm{cmol}_{\mathrm{C}} \mathrm{dm}^{-3} ; \mathrm{Al}^{3+}=$ $1,19 \mathrm{cmol}_{\mathrm{C}} \mathrm{dm}^{-3} ; \mathrm{Na}^{+}=0,06 \mathrm{cmol}_{\mathrm{C}} \mathrm{dm}^{-3} ; \mathrm{H}^{+}+\mathrm{Al}^{3+}=$ $3,84 \mathrm{cmol}_{\mathrm{C}} \mathrm{dm}^{-3} ; \quad \mathrm{S}=3,40 \mathrm{cmol}_{\mathrm{C}} \mathrm{dm}^{-3} ; \quad \mathrm{CTC}=$ $7,24 \mathrm{cmol}_{\mathrm{c}} \mathrm{dm}^{-3}$ e $\mathrm{V}=46,96 \%$.

As análises para caracterização da água do riacho e da água residuária utilizadas na irrigação do experimento, foram realizadas no Laboratório Físico Químico de Esgoto da EMBASA; as amostras foram coletadas no mês de agosto de 2004, em quatro pontos: esgoto bruto, saída do DAFA, saída do alagado construído (wetland) e água do riacho (Tabela 2 ).

Conhecendo-se os valores encontrados, a água residuária foi classificada como $\mathrm{C}_{3} \mathrm{~S}_{1}$ no diagrama para classificação da água, de acordo com o "U. S. Salinity Laboratory Staff" (Salassier, 1995). Conforme com o autor, esta água é altamente salina e não pode ser usada em solos com baixa drenagem mas não possui restrição, em termos de sodicidade. Na classificação de Ayers \& Westcot (1999), freqüentemente empregada para uso de água na irrigação, a água residuária utilizada foi classificada como moderadamente salina e possui ligeira restrição relativa à sodicidade e infiltração do solo.

Entre março e abril de 2005, realizaram-se colheitas e se avaliaram o comprimento das hastes e o número de botões florais das plantas de gladíolo; este mesmo procedimento foi
Tabela 2. Características físico-químicas da água residuária em diferentes etapas do tratamento e da água do riacho

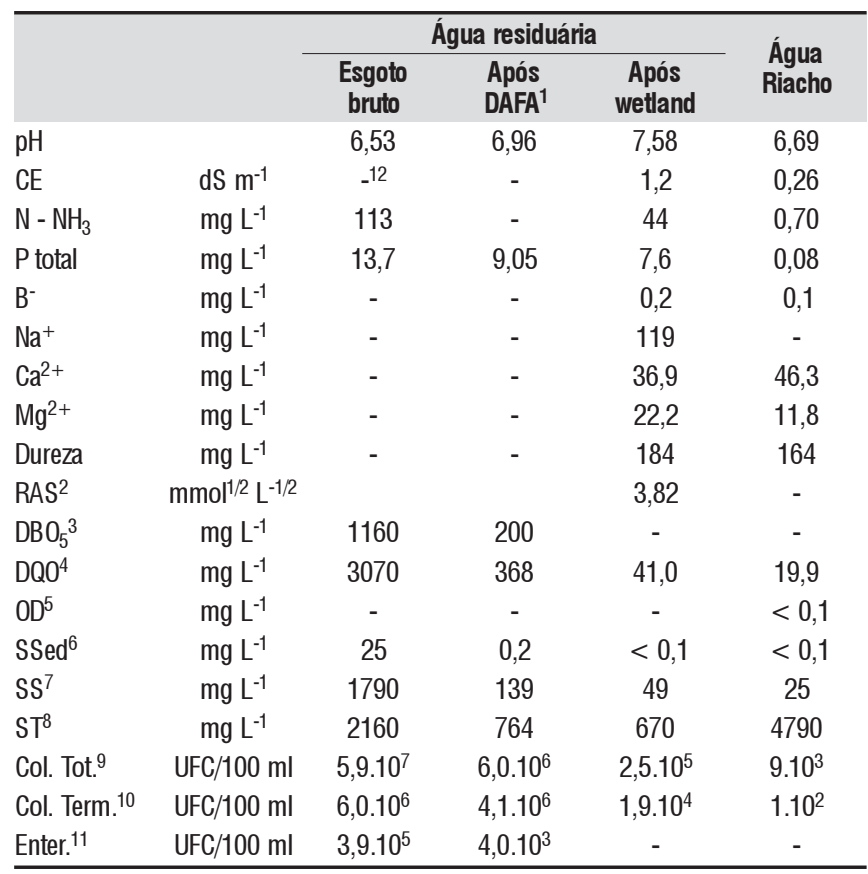

1Digestor Anaeróbico de Fluxo Ascendente; ' 2 Razão de Adsorção de Sódio, ${ }^{3}$ Demanda Bioquímica de Oxigênio, ${ }^{4}$ Demanda Química de Oxigênio, ${ }^{5}$ Oxigênio Dissolvido, ${ }^{6}$ Sólidos Sedimentáveis, ${ }^{7}$ Sólidos Suspensos, ${ }^{8}$ Sólidos totais, ${ }^{9} \mathrm{Coliformes}$ totais, ${ }^{10} \mathrm{Coliformes}$ termotolerantes, ${ }^{11}$ Enterococcus, ${ }^{12}$ valor não determinado

realizado nas plantas de helicônias, entre abril e junho, avaliando-se também a altura das plantas, o número de perfilhos e o diâmetro médio das touceiras. As avaliações foram feitas em 30 plantas por sub-parcela e 90 por tratamento, totalizando 270 plantas para cada espécie; após o término do ciclo (120 dias) o gladíolo foi substituído por plantas floríferas herbáceas e a área continuou sendo irrigada normalmente, com água residuária com e sem desinfecção com cloro e a água do riacho.

Para análise de nutrientes na planta coletaram-se, aos 180 dias após o plantio das helicônias, 3 folhas por planta, em 15 plantas (45 por parcela) e as folhas intermediarias da touceira, livres de ataque de insetos e danos mecânicos. Descartaram-se os pecíolos e se retirou o terço intermediário das folhas, que foi colocado em saco de papel perfurado e levado a secar em estufa com circulação forçada de ar a $65^{\circ} \mathrm{C}$, durante 72 h (Malavolta et al., 1997). As amostras secas foram trituradas em moinho tipo Wiley e encaminhadas ao Laboratório de Fertilidade do Solo e Nutrição Vegetal do Centro de Análises Agrícolas, Campo, MG, para determinação dos teores de N, P, K, Ca, Mg, S, B, Zn, Fe, Mn e Cu.

No mesmo período se retiraram amostras do solo em anéis cilíndricos tipo Uhland na linha de plantio, em três profundidades $0-0,1 \mathrm{~m} ; 0,1-0,2 \mathrm{~m}$ e 0,2-0,3 m para determinação da porosidade, e se coletaram amostras deformadas nas mesmas profundidades para determinação da condutividade elétrica (CE), sódio trocável e percentual de sódio trocável (PST) do solo.

Em uma segunda etapa, aos 360 dias, amostras deformadas de solo foram retiradas para uma avaliação da condutividade elétrica. A extração das pastas de saturação do solo 
foi procedida conforme EMBRAPA (1997) e a CE definida por leitura direta com condutivímetro Tecnal 4MP.

Os dados obtidos foram submetidos a análise de variância e teste F, a nível de 5\% de significância e as médias comparadas pelo teste de Tukey, utilizando-se o Programa estatístico SAEG.

\section{RESULTADOS E DISCUSSÃO}

\section{Qualidade das plantas}

Na Tabela 3 se encontram os resultados das análises referentes à produção de Helicônias. Através do estudo de médias verifica-se, para número de botões florais, comprimento da haste, altura de planta, diâmetro da touceira e número de perfilhos, que não houve significância estatística pelo teste $\mathrm{F}$ a 5\% de probabilidade, para os tipos de água utilizados; este resultado não se assemelha ao de Azevedo \& Oliveira (2005) que obtiveram um aumento na produção de pepino, da ordem de 40,7\%, utilizando águas residuárias; da mesma forma, trabalhos realizados por Mota et al. (1997), mostraram que as culturas de sorgo, de algodão e forrageiras irrigadas com esgoto tratado, tiveram desempenho superior em relação às culturas que receberam água.

Tabela 3. Produção de flores, comprimento da haste floral, perfilhos, altura e diâmetro da touceira das plantas de helicônia e gladíolo irrigadas com três tipos de água*

\begin{tabular}{|c|c|c|c|c|c|}
\hline \multirow[t]{2}{*}{ Tipo de água } & \multirow{2}{*}{$\begin{array}{c}\mathrm{n}^{0} \\
\text { botões }\end{array}$} & $\begin{array}{c}\text { Comp. } \\
\text { haste }\end{array}$ & $\begin{array}{c}\text { Altura } \\
\text { da planta }\end{array}$ & $\begin{array}{c}\emptyset \\
\text { touceira }\end{array}$ & \multirow{2}{*}{$\begin{array}{c}\mathbf{n}^{0} \\
\text { perfilhos }\end{array}$} \\
\hline & & \multicolumn{3}{|c|}{$\mathrm{cm}$} & \\
\hline \multicolumn{6}{|l|}{ Helicônia } \\
\hline AR c/des. ${ }^{1}$ & $4,0 \mathrm{a}$ & $94,9 \mathrm{a}$ & $94,4 \mathrm{a}$ & $114,5 \mathrm{a}$ & $8,7 \mathrm{a}$ \\
\hline AR s/des.? & $3,9 \mathrm{a}$ & $88,6 \mathrm{a}$ & $97,1 \mathrm{a}$ & 117,4 a & $11,2 \mathrm{a}$ \\
\hline Água de riacho & $3,8 \mathrm{a}$ & $86,3 \mathrm{a}$ & 88,3 a & 107,5 a & $8,5 \mathrm{a}$ \\
\hline $\mathrm{CV}^{\beta}(\%)$ & 9,4 & 6,2 & 4,4 & 5,2 & 19,7 \\
\hline \multicolumn{6}{|l|}{ Gladíolo } \\
\hline AR c/des. & $11,7 \mathrm{a}$ & $107,5 \mathrm{a}$ & - & - & - \\
\hline AR s/des. & $12,5 \mathrm{a}$ & $103,3 \mathrm{a}$ & - & - & - \\
\hline Água de riacho & $11,9 \mathrm{a}$ & 109,8 a & - & - & - \\
\hline CV (\%) & 8,4 & 5,7 & & & \\
\hline
\end{tabular}

*Médias seguidas da mesma letra não diferem significativamente entre si pelo teste de Tukey a $5 \%$. ${ }^{1}$ Água residuária tratada desinfetada com cloro, ${ }^{2}$ Água residuária tratada, ${ }^{3}$ coeficiente de variação

Embora as variáveis altura de planta, diâmetro da touceira e número de perfilhos, não tenham apresentado diferenças estatísticas das demais, seus valores numéricos foram superiores quando utilizada a água residuária sem desinfecção. É provável que isto se deva ao fato da água do riacho possuir baixíssimas concentrações de nutrientes (Tabela 2), especialmente de fósforo, que acelera a formação de raízes, e do nitrogênio, cuja função é estimular a formação e o desenvolvimento de gemas floríferas e proporcionar maior vegetação e perfilhamento às plantas (Malavolta et al., 1997); já os teores de matéria orgânica, importante para o sistema solo-planta (Stevenson, 1994), e de nutrientes contidos no esgoto doméstico, apresentam valor potencial para as produções agrícolas (Telles, 2003); por outro lado, o pouco tem- po de irrigação pode ter contribuído para a não significância dos tratamentos, visto que as helicônias têm ciclo longo e as avaliações foram feitas entre os quinto e sexto meses após o plantio, quando as plantas estavam ainda em desenvolvimento, emitindo suas primeiras inflorescências.

Conforme os dados apresentados na Tabela 3, o número de botões florais e os valores referentes ao comprimento da haste floral, relativos à produção de gladíolo, não apresentaram significância estatística para os tipos de água utilizados; quando, porém, comparadas pelo teste de Tukey, as médias não diferiram significativamente entre si. Papadopolous \& Stylianou (1991), encontraram resultados diferentes quando irrigaram com água residuária plantas de girassol, o que proporcionou alto rendimento e boa qualidade em sementes; esta semelhança entre as médias do número de botões e comprimento da haste do gladíolo, mesmo com a diferença de teores de nutrientes nas diferentes águas (Tabela 2), pode ter sido em decorrência do pouco tempo de utilização da irrigação, que foi insuficiente para promover mudanças químicas apreciáveis no solo; além disso, como a área recebeu calcário antes do plantio, nutrientes como Ca e Mg possivelmente já existiam no solo em quantidades maiores que as acrescentadas com a irrigação; então, é provável que a adubação orgânica tenha sido a única fonte de nutriente utilizada pelo gladíolo.

\section{Análise de nutrientes das folhas de helicônia}

Apresentam-se, na Tabela 4, os resultados dos valores médios dos macronutrientes $\mathrm{N}, \mathrm{P}, \mathrm{K}, \mathrm{Ca}, \mathrm{Mg}$ e $\mathrm{S}$, encontrados nas folhas da helicônia; observa-se que apenas o $\mathrm{N}, \mathrm{Mg}$ e S, estão dentro da faixa dos níveis de nutrientes definidos para Heliconia spp, segundo Atehortua apud Lamas (2003), são: $\mathrm{N}=31-38 \mathrm{~g} \mathrm{~kg}^{-1} ; \mathrm{P}=20-40 \mathrm{~g} \mathrm{~kg}^{-1} ; \mathrm{K}=35-45 \mathrm{~g} \mathrm{~kg}^{-1}$; $\mathrm{Ca}=12,6-17,5 \mathrm{~g} \mathrm{~kg}^{-1} ; \mathrm{Mg}=2,5-8 \mathrm{~g} \mathrm{~kg}^{-1} ; \mathrm{S}=2,5-8 \mathrm{~g} \mathrm{~kg}^{-1}$; $\mathrm{B}=10-75 \mathrm{mg} \mathrm{kg}^{-1} ; \mathrm{Cu}=6-25 \mathrm{mg} \mathrm{kg}^{-1} ; \mathrm{Fe}=76-300 \mathrm{mg} \mathrm{kg}^{-1}$; $\mathrm{Mn}=100-1000 \mathrm{mg} \mathrm{kg}^{-1} ; \mathrm{Zn}=26-250 \mathrm{mg} \mathrm{kg}^{-1}$.

Conforme os valores mencionados, verifica-se ainda que o Ca e o K estão abaixo do nível de suficiência exigido pela planta. Em situação mais crítica se encontra o P, que apresentou apenas 9,5\% do mínimo (20 g kg-1) (Atehortua apud Lamas, 2003) requerido pela cultura determinando, assim, um déficit acentuado. Blum (2003) ressalta que os teores de $\mathrm{P}$ em águas recuperadas de esgoto, em geral não atendem às necessidades das plantas, motivando uma adubação suplementar.

Ao se analisar a Tabela 2 na qual se encontram os resultados das características químicas da água residuária e da água do riacho utilizadas na irrigação da helicônia, observa-se que os níveis de $\mathrm{N}$ (amônia) $\mathrm{NH}_{3}(\mathrm{~N})$, fósforo total e magnésio, são bastante inferiores na água do riacho; apenas o nível de cálcio foi superior ao do wetland (46,3 e $36,9 \mathrm{mg} \mathrm{L}^{-1}$, respectivamente); contudo, os resultados indicados na Tabela 4 demonstram ausência de diferença significativa no teor desses elementos $(+K)$ nas folhas de helicônia irrigada com água residuária (com ou sem desinfecção) e água do riacho.

A Tabela 4 apresenta os teores médios dos micronutrientes B, Zn, Fe, Mn e Cu, encontrados nas folhas de helicônia. 
Tabela 4. Teores de macro e microelementos encontrados nas folhas de helicônias irrigadas com três tipos de água*

\begin{tabular}{|c|c|c|c|c|c|c|c|c|c|c|c|}
\hline \multirow{2}{*}{ Tratamento } & $\mathrm{N}$ & $\mathbf{P}$ & K & $\mathrm{Ca}$ & $\mathrm{Mg}$ & $S$ & B & $\mathrm{Zn}$ & $\mathrm{Fe}$ & $M n$ & $\mathrm{Cu}$ \\
\hline & \multicolumn{6}{|c|}{$\mathrm{g} \mathrm{kg}^{-1}$} & \multicolumn{5}{|c|}{$\mathrm{mg} \mathrm{kg}^{-1}$} \\
\hline AR c/des. ${ }^{1}$ & $32,4 \mathrm{a}$ & $1,90 \mathrm{a}$ & $14,4 \mathrm{a}$ & $4,17 \mathrm{a}$ & $2,83 \mathrm{a}$ & $3,93 \mathrm{a}$ & $13,7 \mathrm{a}$ & $18,0 \mathrm{a}$ & $219,0 \mathrm{a}$ & $685,0 \mathrm{a}$ & $19,0 \mathrm{a}$ \\
\hline AR s/des.? & $32,2 \mathrm{a}$ & $1,93 \mathrm{a}$ & $14,0 \mathrm{a}$ & $4,07 \mathrm{a}$ & $2,87 \mathrm{a}$ & $3,93 \mathrm{a}$ & $13,7 \mathrm{a}$ & $19,7 \mathrm{a}$ & $202,0 \mathrm{a}$ & $636,0 \mathrm{a}$ & $19,3 \mathrm{a}$ \\
\hline Água de riacho & $30,6 \mathrm{a}$ & $1,87 \mathrm{a}$ & $16,5 \mathrm{a}$ & $4,40 \mathrm{a}$ & $2,77 \mathrm{a}$ & $3,87 \mathrm{a}$ & $12,7 \mathrm{a}$ & $18,7 \mathrm{a}$ & $230,0 \mathrm{a}$ & $550,0 \mathrm{a}$ & $20,7 \mathrm{a}$ \\
\hline $\mathrm{CV}^{3}(\%)$ & 6,32 & 2,14 & 20,65 & 3,16 & 1,86 & 5,08 & 6,8 & 9,6 & 13,5 & 21,0 & 11,7 \\
\hline
\end{tabular}

Embora os níveis de Fe sejam numericamente superiores nas plantas irrigadas com água do riacho, os tratamentos não mostraram diferença significativa entre si em relação aos microelementos analisados. Ao se analisar os teores dos micronutrientes encontrados em folhas de helicônias, definidos por Atehortua apud Lamas (2003), constata-se que os valores de $\mathrm{B}, \mathrm{Fe}$, Mn e Cu estão dentro do limite de exigência, porém a quantidade do Zn não foi suficiente para atender, segundo o mesmo autor, ao limite mínimo de $26 \mathrm{mg} \mathrm{kg}^{-1}$ exigido pela planta. A carência de zinco acarreta diminuição de tamanho das folhas novas, além do seu estreitamento e alongamento (Malavolta et al., 1997), sintomas que não foram observados nas plantas analisadas.

\section{Salinidade do solo}

O desenvolvimento das plantas é afetado diretamente pela salinidade do solo (Ayers \& Westcot, 1999), em virtude do potencial osmótico gerado pela presença de sais no solo; então, o rendimento das culturas cai proporcionalmente ao aumento da salinidade do solo, aqui avaliada através da condutividade elétrica.

Os valores médios das análises de condutividade elétrica do solo da área experimental após 180 dias de irrigação, estão apresentados na Tabela 5, na qual se encontram os dados referentes à área plantada com helicônia e com gladíolo.

A comparação das médias apresentada na Tabela 5, demonstra claramente que não houve diferença estatística entre os valores de CE do solo irrigado com água do riacho ou com água residuária com e sem desinfecção; possivelmente, o tempo de irrigação foi insuficiente para promover uma diferença entre os tratamentos; todavia, a condutividade elétrica do solo encontrada na área em que foi cultivado o gladíolo, foi ligeiramente superior em valores numéricos à da área cultivada com a helicônia o que se deve, sem dúvida, ao fato de que, nesta área, o solo ficou mais descoberto e portanto, mais exposto ao processo de evaporação em razão da morfologia da planta do gladíolo proporcionar uma área de cobertura foliar menor que a da helicônia.

Embora não haja diferença estatística para os valores da CE entre os tratamentos testados, verifica-se o inverso entre as profundidades (letras minúsculas, Tabela 5); a irrigação das plantas de helicônia com o efluente desinfetado levou a uma diferença significativa de CE entre as profundidades 0,0-0,1 m e 0,2-0,3 m, tal como ocorreu na área das plantas de gladíolo, embora a profundidade de 0,2-0,3 m tenha apresentado valor inferior e diferido estatisticamente das demais.

A utilização da água residuária não desinfetada não mostrou diferença significativa em nenhuma das profundidades
Tabela 5. Condutividade elétrica do solo em três profundidades, cultivado com helicônias e gladíolos irrigados com água residuária tratada (AR) e água do riacho*

\begin{tabular}{|c|c|c|c|c|}
\hline Prof. (m) & $\begin{array}{c}\text { AR c/ } \\
\text { desinfecção }\end{array}$ & $\begin{array}{c}\text { AR s/ } \\
\text { desinfecção }\end{array}$ & $\begin{array}{c}\text { Água do } \\
\text { riacho }\end{array}$ & Média \\
\hline \multicolumn{5}{|c|}{ Solo cultivado com helicônia } \\
\hline \multicolumn{5}{|c|}{6 meses de cultivo } \\
\hline $0,0-0,1$ & $0,375 \mathrm{Aa}$ & $0,390 \mathrm{Aa}$ & $0,416 \mathrm{Aa}$ & $0,394 \mathrm{a}$ \\
\hline $0,1-0,2$ & 0,348 Aab & $0,382 \mathrm{Aa}$ & $0,331 \mathrm{Ab}$ & $0,353 a b$ \\
\hline $0,2-0,3$ & $0,289 \mathrm{Ab}$ & $0,340 \mathrm{Aa}$ & $0,319 \mathrm{Ab}$ & $0,316 \mathrm{~b}$ \\
\hline média & $0,337 \mathrm{~A}$ & $0,370 \mathrm{~A}$ & $0,355 \mathrm{~A}$ & \\
\hline \multicolumn{5}{|c|}{12 meses de cultivo } \\
\hline $0,0-0,1$ & $0,680 \mathrm{Aa}$ & $0,602 \mathrm{Aa}$ & $0,377 \mathrm{Ba}$ & $0,553 \mathrm{a}$ \\
\hline $0,1-0,2$ & $0,550 \mathrm{Aab}$ & $0,522 \mathrm{Aa}$ & $0,373 \mathrm{Ba}$ & $0,481 a b$ \\
\hline $0,2-0,3$ & $0,489 \mathrm{Ab}$ & $0,470 \mathrm{Aa}$ & $0,254 \mathrm{Ba}$ & $0,404 \mathrm{~b}$ \\
\hline média & $0,573 \mathrm{~A}$ & $0,531 \mathrm{~A}$ & $0,335 \mathrm{~B}$ & \\
\hline \multicolumn{5}{|c|}{ Solo cultivado com gladíolos } \\
\hline \multicolumn{5}{|c|}{6 meses de cultivo } \\
\hline $0,0-0,1$ & $0,446 \mathrm{Aa}$ & $0,438 \mathrm{Aa}$ & $0,456 \mathrm{Aa}$ & $0,447 \mathrm{a}$ \\
\hline $0,1-0,2$ & $0,436 \mathrm{Aa}$ & $0,413 \mathrm{Aa}$ & $0,368 \mathrm{Ab}$ & $0,406 \mathrm{a}$ \\
\hline $0,2-0,3$ & $0,308 \mathrm{Ab}$ & $0,365 \mathrm{Aa}$ & $0,356 \mathrm{Ab}$ & $0,343 \mathrm{~b}$ \\
\hline média & $0,397 \mathrm{~A}$ & $0,406 \mathrm{~A}$ & $0,394 \mathrm{~A}$ & \\
\hline \multicolumn{5}{|c|}{12 meses de cultivo } \\
\hline $0,0-0,1$ & $0,843 \mathrm{Aa}$ & $0,602 \mathrm{Ba}$ & $0,437 \mathrm{Ca}$ & $0,627 \mathrm{a}$ \\
\hline $0,1-0,2$ & $0,674 \mathrm{Ab}$ & $0,661 \mathrm{Aa}$ & $0,369 \mathrm{Ba}$ & $0,568 \mathrm{a}$ \\
\hline $0,2-0,3$ & $0,668 \mathrm{Ab}$ & $0,694 \mathrm{Aa}$ & $0,347 \mathrm{Ba}$ & $0,569 \mathrm{a}$ \\
\hline média & $0,728 \mathrm{~A}$ & $0,653 \mathrm{~A}$ & $0,384 \mathrm{~A}$ & \\
\hline
\end{tabular}

*Médias seguidas de letras iguais (maiúsculas na linha e minúsculas nas colunas) não diferem significativamente entre si pelo teste de Tukey a $5 \%$

analisadas nas áreas cultivadas com as diferentes espécies porém a água do riacho proporcionou a diferença estatística da profundidade $0,0-0,1 \mathrm{~m}$ sobre as $0,1-0,2 \mathrm{~m}$ e $0,2-0,3 \mathrm{~m}$, as quais não se diferenciaram nas áreas plantadas com as duas espécies; é provável que esta diferença se deva ao fato da água de riacho conter quantidades mínimas de sais, devido ao processo evapotranspirativo (Bernstein, 1974) que tendem a ascender, concentrando-se apenas na camada superficial (0,0-0,1 m).

Ao se comparar os valores encontrados na caracterização da área experimental, apresentados na Tabela 1, vê-se que a condutividade elétrica do solo, nas profundidades 0,0-0,1 m $\left(0,342 \mathrm{dS} \mathrm{m}^{-1}\right), \quad 0,1-0,2 \mathrm{~m}\left(0,299 \mathrm{dS} \mathrm{m}^{-1}\right)$ e $0,2-0,3 \mathrm{~m}$ $\left(0,239 \mathrm{dS} \mathrm{m}^{-1}\right)$, sofreu um leve aumento numérico em relação aos 180 dias após o início da irrigação (Tabela 5) devido à presença de sais na água (Gloaguen et al., 2007).

Segundo Lima (1997), as plantas absorvem água do solo juntamente com os sais e, a depender da sua concentração e da sensibilidade da planta, pode ocorrer toxidez cujo excesso 
promove desbalanços no citoplasma, fazendo com que os danos surjam principalmente nas bordas e nos ápices das folhas, regiões onde ocorre o acúmulo dos sais absorvidos; contudo, o aumento da salinidade do solo nas parcelas analisadas, aparentemente não afetou as plantas de helicônia e gladíolos, visto que as mesmas não apresentaram qualquer sintoma característico de deficiência hídrica associado ao decréscimo do potencial osmótico no solo.

Os valores de condutividade elétrica do solo após 360 dias de irrigação com água residuária (Tabela 5) foram superiores aos mesmos valores após 180 dias de irrigação, evidenciando o impacto desta prática na salinidade do solo.

Na parcela plantada com helicônia o aumento foi de 70,0 e 43,4\% (média das três profundidades), respectivamente para as parcelas irrigadas com água residuária desinfetada e não desinfetada, enquanto na parcela em que o gladíolo foi cultivado os aumentos foram de 83,6 e 60,8\%. Supõe-se que a diferença de valor de CE entre os dois tratamentos se deve ao cloro adicionado ao efluente desinfetado. O solo irrigado com água de riacho apresentou leve decréscimo de CE (-5,8\%) em relação ao valor, depois de 180 dias de irrigação, o que foi atribuído à calagem e adubação orgânica no início do experimento seguido de uma leve lixiviação desses sais, ao longo do ano. O valor significativamente mais alto na profundidade 0,0-0,1 m que nas demais aos 180 dias de irrigação, confirma esta hipótese.

Em relação às profundidades e independente do tratamento e do período de irrigação, observa-se que a CE é mais alta na superfície do solo $(0,0-0,1 \mathrm{~m})$; este fato é esperado em solo irrigado, em razão do fenômeno de evapotranspiração (Bernstein, 1974).

Apesar do aumento da concentração da salinidade após 360 dias do início da irrigação, as plantas de helicônia não apresentaram sintomas nas bordas nem nos ápices das folhas, regiões onde ocorre o acúmulo dos sais absorvidos (Lima, 1997).

\section{Sodicidade e estrutura do solo}

Embora a salinidade seja o maior fator limitante ao desenvolvimento e rendimento das culturas, elas podem ser afetadas direta e indiretamente, pela sodicidade; diretamente, quando o sódio em alta concentração na água de irrigação se torna elemento tóxico para a planta. Ayers \& Westcot (1999) propuseram um valor de 0,25 a $0,50 \%$ de sódio no tecido das folhas (com base no peso seco), como valor crítico de toxidez, apesar de variar muito em função do tipo de planta (valor proposto para árvores); assim, culturas como algodão, alfafa, cevada e beterraba, são tolerantes à sodicidade, enquanto feijão, milho, ervilha, amendoim e lentilha, são sensíveis, (rendimento afetado com Percentual de Sódio Trocável no solo - PST < 15\%).

O grau de restrição em termos de toxidez pelo $\mathrm{Na}^{+}$pode ser avaliado na água de irrigação (Ayers \& Westcot, 1999). Neste trabalho, o conteúdo de sódio na água residuária tem valor aproximado de $119 \mathrm{mg} \mathrm{L}^{-1}$, ou seja, 5,2 mmol $_{\mathrm{C}} \mathrm{L}^{-1}$ (Tabela 2), o que a classifica como moderadamente tóxica porém este valor é variável em função da espécie. Como não se observaram sinais típicos de toxidez por sódio, tais como queimadura ou necrose ao longo das bordas, conclui-se so- bre a relativa tolerância dessas plantas à toxidez pelo sódio.

O conteúdo de sódio no solo também pode afetar indiretamente o desenvolvimento das plantas, através do efeito dispersante do sódio nas argilas alterando, conseqüentemente, a estrutura do solo (Gloaguen, 2005; Gonçalves et al., 2007); neste estudo, a água residuária apresentou grau de restrição ligeira a moderada (RAS $=3,83 \mathrm{mmol}^{1 / 2} \mathrm{~L}^{-1 / 2}$; $\mathrm{CE}=1,2 \mathrm{dS} \mathrm{m}^{-1}$ ) o que justifica o estudo da sodicidade do solo e do efeito na sua estrutura.

Os resultados da sodicidade do solo são apresentados na Tabela 6, expressos em termos de conteúdo de sódio $\left(\mathrm{mmol}_{\mathrm{c}}\right.$ de $\mathrm{Na}^{+}$trocável por $\mathrm{dm}^{3}$ de solo) e PST (percentual de $\mathrm{Na}^{+}$ trocável no solo). Apesar de um aporte de $8,3 \mathrm{mmol}_{\mathrm{C}} \mathrm{dm}^{-2}$ de $\mathrm{Na}^{+}$(concentração x lâmina total) pela água residuária, os valores de $\mathrm{Na}^{+}$trocável no solo e, conseqüentemente, de PST, foram baixos (valores sempre inferiores ou iguais a $0,1 \mathrm{mmol}_{\mathrm{C}} \mathrm{dm}^{-3}$ e $1,2 \%$, respectivamente) e muito menores que os observados em outros experimentos de irrigação com efluente de lagoas de estabilização de esgoto em Latossolo (Fonseca, 2005; Gloaguen, 2006). Nos estudos mencionados, o conteúdo de $\mathrm{Na}^{+}$foi sempre superior a $1,8 \mathrm{mmol}_{\mathrm{C}} \mathrm{dm}^{-3}$ (no mínimo 18 vezes maior que no presente trabalho); além disso, os experimentos de Fonseca (2005) e Gloaguen (2006) foram conduzidos em Latossolo com cerca de $72 \%$ de areia e $13 \%$ de argila, enquanto o solo aqui estudado apresentou textura argilo-siltosa (Tabela 1) com 8,0\% de areia e 51,5\% de argila no perfil de 0,0-0,3 m; desta forma, altos valores de $\mathrm{Na}^{+}$ trocável eram esperados neste solo argiloso que possui maior capacidade de troca catiônica que um solo arenoso.

Decerto, este baixo conteúdo de $\mathrm{Na}^{+}$se deveu, provavelmente, ao curto intervalo de tempo da irrigação (180 dias), combinado com a precipitação elevada (1600 a $2000 \mathrm{~mm}$ ) que ocorre na região, sobretudo na primeira metade do ano; então, se um acúmulo de $\mathrm{Na}^{+}$tivesse ocorrido no início do cultivo

Tabela 6. Sodicidade do solo expressa pelo teor de sódio ( $\mathrm{Na}^{+}$trocável) e percentual de sódio trocável (PST) no solo cultivado com helicônia e gladíolo irrigados com água residuária tratada (AR) e água de riacho*

\begin{tabular}{|c|c|c|c|}
\hline Prof. (m) & AR c/desinfecção & AR s/desinfecção & Água do riacho \\
\hline \multicolumn{4}{|c|}{ Solo cultivado com helicônia } \\
\hline & \multicolumn{3}{|c|}{$\mathrm{Na}^{+}$trocável $\left(\mathrm{mmol}_{\mathrm{c}} \mathrm{dm}^{-3}\right)$} \\
\hline $0,0-0,1$ & $0,10 \mathrm{aA}$ & $0,10 \mathrm{aA}$ & $0,10 \mathrm{aA}$ \\
\hline $0,1-0,2$ & $0,03 \mathrm{aA}$ & $0,10 \mathrm{aA}$ & $0,07 \mathrm{aA}$ \\
\hline \multirow[t]{2}{*}{$0,2-0,3$} & $0,07 \mathrm{aA}$ & $0,10 \mathrm{aA}$ & $0,03 \mathrm{aA}$ \\
\hline & \multicolumn{3}{|c|}{ PST (\%) } \\
\hline $0,0-0,1$ & 0,97 & 0,96 & 0,92 \\
\hline $0,1-0,2$ & 0,39 & 1,05 & 0,65 \\
\hline $0,2-0,3$ & 0,78 & 1,18 & 0,38 \\
\hline \multicolumn{4}{|c|}{ Solo cultivado com gladíolo } \\
\hline & \multicolumn{3}{|c|}{$\mathrm{Na}^{+}$trocável $\left(\mathrm{mmol}_{\mathrm{c}} \mathrm{dm}^{-3}\right)$} \\
\hline $0,0-0,1$ & $0,10 \mathrm{Aa}$ & $0,10 \mathrm{Aa}$ & $0,10 \mathrm{Aa}$ \\
\hline $0,1-0,2$ & $0,10 \mathrm{Aa}$ & $0,10 \mathrm{Aa}$ & $0,10 \mathrm{Aa}$ \\
\hline $0,2-0,3$ & $0,07 \mathrm{Aa}$ & $0,07 \mathrm{Aa}$ & $0,07 \mathrm{Aa}$ \\
\hline & \multicolumn{3}{|c|}{ PST (\%) } \\
\hline $0,0-0,1$ & 0,97 & 0,89 & 0,94 \\
\hline $0,1-0,2$ & 1,06 & 0,96 & 1,00 \\
\hline $0,2-0,3$ & 0,82 & 0,76 & 0,73 \\
\hline
\end{tabular}

*Médias seguidas de letras iguais (maiúsculas na linha e minúsculas na coluna) não diferem significativamente entre si pelo teste de Tukey a $5 \%$ 
por conta da irrigação, os eventos chuvosos de maio, junho e julho poderiam lixiviar o $\mathrm{Na}^{+}$ainda não equilibrado na CTC (equilíbrio mais lento na microporosidade preponderante Tabela 1). A ocorrência da lixiviação que não permitiu acúmulo de sais na superfície do solo $(0,0-0,3 \mathrm{~m})$ demonstra que a irrigação não afetou, a curto prazo, as propriedades físicohídricas do solo (boa percolação de água no solo), fazendo com que os valores de sodicidade do solo fossem similares aos obtidos no solo irrigado água do riacho.

Os dados da porosidade do solo (Tabela 7), incluindo porosidade total e, mais especificamente, a distribuição da porosidade, permitem observar se a adição de sais através da água residuária tem efeito ou não na estrutura do solo.

Tabela 7. Proporção entre microporosidade, macroporosidade e volume de sólidos no solo cultivado com helicônia irrigada com água residuária tratada (AR) e água do riacho*

\begin{tabular}{|c|c|c|c|}
\hline Prof. (m) & AR c/ desinfecção & AR s/ desinfecção & Água do riacho \\
\hline \multicolumn{4}{|c|}{ Solo cultivado com helicônia } \\
\hline & \multicolumn{3}{|c|}{ Macroporosidade (\% do volume total) } \\
\hline $0,0-0,1$ & 2,2 Aa & $2,4 \mathrm{Aa}$ & $3,0 \mathrm{Aa}$ \\
\hline $0,1-0,2$ & $2,8 \mathrm{Aa}$ & $2,1 \mathrm{Aa}$ & $3,8 \mathrm{Aa}$ \\
\hline \multirow[t]{2}{*}{$0,2-0,3$} & $4,2 \mathrm{Aa}$ & $2,0 \mathrm{Aa}$ & $2,3 \mathrm{Aa}$ \\
\hline & \multicolumn{3}{|c|}{ Microporosidade (\% do volume total) } \\
\hline $0,0-0,1$ & $41,0 \mathrm{Aa}$ & $41,9 \mathrm{Aa}$ & $41,6 \mathrm{Aa}$ \\
\hline $0,1-0,2$ & 38,7 Aab & $39,3 \mathrm{Aa}$ & 37,8 Aab \\
\hline \multirow[t]{2}{*}{$0,2-0,3$} & $36,3 \mathrm{Bb}$ & $39,9 \mathrm{Aa}$ & $38,7 \mathrm{ABb}$ \\
\hline & \multicolumn{3}{|c|}{ Sólidos (\% do volume total) } \\
\hline $0,0-0,1$ & $56,8 \mathrm{Aa}$ & $55,7 \mathrm{Aa}$ & $55,4 \mathrm{Aa}$ \\
\hline $0,1-0,2$ & $58,5 \mathrm{Aa}$ & $58,6 \mathrm{Aa}$ & $58,4 \mathrm{Aa}$ \\
\hline $0,2-0,3$ & $59,6 \mathrm{Aa}$ & $58,1 \mathrm{Aa}$ & $59,0 \mathrm{Aa}$ \\
\hline \multicolumn{4}{|c|}{ Solo cultivado com gladíolo } \\
\hline & \multicolumn{3}{|c|}{ Macroporosidade (\% do volume total) } \\
\hline $0,0-0,1$ & $2,4 \mathrm{Aa}$ & $0,9 \mathrm{Aa}$ & $1,3 \mathrm{Aa}$ \\
\hline $0,1-0,2$ & $5,2 \mathrm{Aa}$ & $1,4 \mathrm{Ba}$ & $1,1 \mathrm{Ba}$ \\
\hline \multirow[t]{2}{*}{$0,2-0,3$} & $0,9 \mathrm{Ab}$ & $1,2 \mathrm{Aa}$ & $0,9 \mathrm{Aa}$ \\
\hline & \multicolumn{3}{|c|}{ Microporosidade (\% do volume total) } \\
\hline $0,0-0,1$ & $39,8 \mathrm{Aa}$ & $42,3 \mathrm{Aa}$ & $40,4 \mathrm{Aa}$ \\
\hline $0,1-0,2$ & $36,8 \mathrm{Aa}$ & $39,1 \mathrm{Aab}$ & $38,0 \mathrm{Aa}$ \\
\hline \multirow[t]{2}{*}{$0,2-0,3$} & $39,3 \mathrm{Aa}$ & $38,3 \mathrm{Ab}$ & $38,2 \mathrm{Aa}$ \\
\hline & \multicolumn{3}{|c|}{ Sólidos (\% do volume total) } \\
\hline $0,0-0,1$ & $57,8 \mathrm{Aa}$ & $56,8 \mathrm{Aa}$ & $58,3 \mathrm{Aa}$ \\
\hline $0,1-0,2$ & $58,0 \mathrm{Aa}$ & $59,5 \mathrm{Aa}$ & $60,9 \mathrm{Aa}$ \\
\hline $0,2-0,3$ & 59,8 Aa & $60,5 \mathrm{Aa}$ & $61,0 \mathrm{Aa}$ \\
\hline
\end{tabular}

*Médias seguidas de letras iguais (maiúsculas na linha e minúsculas na coluna) não diferem significativamente entre si pelo teste de Tukey a $5 \%$

Não se observou diferença significativa na macroporosidade, microporosidade nem no volume de sólidos entre tratamentos, para as duas espécies estudadas, exceto em dois casos isolados. Comparando-se as profundidades, tem-se que os valores de macro e microporosidade foram, em geral maiores a $0-0,1 \mathrm{~m}$ do que a 0,2-0,3 $\mathrm{m}$ de profundidade (4 diferenças significativas), ilustrando o efeito natural das raízes e do acúmulo de matéria orgânica fresca na aeração e formação de agregados na camada superficial do solo.

Segundo Gloaguen (2005) o esgoto tratado, notadamente os domésticos, têm ação modificadora no meio poroso, especialmente em solos tropicais, devido à presença de altas con- centrações de $\mathrm{Na}^{+}$. A dispersão e a expansão das argilas, que são fenômenos freqüentemente observados em solos sódicos ou irrigados com águas sódicas, ocorrem a partir de um valor crítico de PST. O valor crítico para expansão de 15\% (Sumner, 1993) não foi observado no final do experimento (Tabela 6) e, provavelmente, não foi atingindo ao longo do experimento, haja vista que o tempo de equilíbrio entre o $\mathrm{Na}^{+}$na fase líquida e sólida é geralmente longo (de um a dois anos).

Desta forma, é provável que os resultados deste trabalho não tenham apresentado diferenças em razão da baixa sodicidade no solo aliada ao tempo insuficiente de irrigação, o que não permitiu que mudanças evidentes tivessem ocorrido na porosidade.

\section{CONCLUSÕES}

1. O número de botões florais, comprimento da haste, altura de planta, diâmetro da touceira, número de perfilhos da helicônia, o número de botões florais e o comprimento da haste do gladíolo, não foram influenciados de forma significativa pela irrigação com água residuária.

2. Observou-se que a irrigação com água residuária com e sem desinfecção com cloro não exerceu qualquer diferenciação nos teores de macro e micronutrientes absorvidos pelas plantas de helicônia.

3. O uso da água residuária na irrigação levou ao aumento dos teores de sais, principalmente na camada superficial do solo, após um ano de experimento.

4. O fator tempo é determinante na mudança das propriedades, o que sugere cuidados quando se usa água residuária em um período maior a 12 meses.

\section{LITERATURA CITADA}

Ayers, R. S.; Westcot, D. W. A qualidade da água na agricultura. Campina Grande: UFPB, 1999. 218p.

Azevedo, L. P. de; Oliveira, E. L. de. Efeitos da aplicação de efluente de tratamento de esgoto na fertilidade do solo e produtividade de pepino sob irrigação subsuperficial. Engenharia Agrícola, v.25, n.1, p.253-263, 2005.

Bernardi, C. C. Reúso de água para irrigação. Brasília: UnB, 2003. 52p. Dissertação Mestrado

Bernstein, I. Crops growth and salinity. In: Schhilfgarde, I. V. (ed.). Drainage for agriculture. Madison: American Society of Agronomy, 1974. p.39-99.

Blum, J. R. C. Critérios e padrões de qualidade da água. In: Mancuso, P.C.S.; Santos, H. F. (ed.). Reúso de água. São Paulo: Manole, 2003. p.125-174.

EMBRAPA - Empresa Brasileira de Pesquisa Agropecuária. Centro Nacional de Pesquisa de Solos. Manual de métodos de análise de solo. 2.ed. Rio de Janeiro: EMBRAPA, 1997. 212p.

Folegatti, M. V.; Duarte, A. S.; Gonçalves, R. A. B. Uso de águas residuárias na agricultura: In: Workshop de Uso e Reúso de Águas de Qualidade Inferior: Realidades de Perspectivas, 1, 2005, Campina Grande. Resumos... Campina Grande: UFCG, 2005. CD Rom. 
Fonseca, A. F, da. Variabilidade agronômico-ambiental da disposição de efluente de esgoto tratado em um sistema solo-pastagem. Piracicaba: ESALQ/USP, 2005. 174p. Tese Doutorado

Gloaguen, R. A. B. G. Efeito da irrigação com efluente de esgoto tratado nas propriedades físico-hídricas de um Latossolo. Piracicaba: ESALQ/USP, 2005. 119p. Tese Doutorado

Gloaguen, T. V. Transferências de espécies químicas através de um solo cultivado com milho e girassol irrigado com efluente de esgoto doméstico. São Paulo: IGC/USP, 2006. 113p. Tese Doutorado

Gloaguen, T. V.; Forti, M. C.; Lucas, Y.; Montes, C. R.; Gonçalves, R. A. B.; Herpin, U.; Melfi, A. J. Soil solution chemistry of a Brazilian Oxisol irrigated with treated sewage effluent. Agricultural Water Management, v.88, p.119-131, 2007.

Gonçalves, R. A. B.; Folegatti, M. V.; Gloaguen, T. V.; Libardi, P. L.; Montes, C. R.; Lucas, Y.; Dias, C. T. S.; Melfi, A. J. Hydraulic conductivity of a soil irrigated with treated sewage effluent. Geoderma, v.139, p.241-248, 2007.

Hespanhol, I. Potencial de reúso de água no Brasil: Agricultura, indústria, municípios, recarga de aqüíferos. Bahia Análise \& Dados, v.13, p.411-437, 2003.

Lamas, A. da M. Floricultura tropical: avanços tecnológicos. In: Semana Internacional da Fruticultura, Floricultura e Agroindústria, 10, 2003, Fortaleza. Anais... Fortaleza: Instituto Frutal, 2003. CD Rom.

Lemos; R. C. de; Santos, R. D. dos. Manual de descrição e coleta de solo no campo. 3.ed. Campinas: Sociedade Brasileira de Solo, 1996. 86p.

Lima, L. A. Efeitos de sais no solo e na planta. In: Congresso Brasileiro de Engenharia Agrícola, 26, 1997, Campina Grande. Resumos... Campina Grande: UFPB/SBEA, 1997. p.113-136.
Malavolta, E.; Vitti, G. C.; Oliveira, S. A. de. Avaliação do estado nutricional das plantas: Princípios e aplicações. 2.ed. Piracicaba: POTAFOS, 1997. 319p.

Mota, S.; Bezerra, F. C.; Tomé, L. M. Avaliação do desempenho de culturas irrigadas com esgotos tratados. Congresso Brasileiro de Engenharia Sanitária e Ambiental, 19, 1997, Foz do Iguaçu. Anais... Foz do Iguaçu: Associação Brasileira de Engenharia Sanitária e Ambiental, 1997. p.20-26.

Papadopoulos, I.; Stylianou, Y. Trickle irrigation of sunflower with municipal wastewater. Agricultural Water Management, v.19, n.1, p.67-75, 1991.

Pescod, M. D. Wastewater treatment and use in agriculture (FAO, Irrigation and drainage paper, 47). Rome: FAO, 1992. 125p

Rhoades, J. D.; Kandiah, A.; Mashali, A. M. Uso de águas salinas para produção agrícola. Campina Grande: UFPB, 2000. 117p.

Salassier, B. Manual de irrigação. Viçosa: UFV, 1995. 657p.

Sousa, J. T. de; Leite, V. D. Tratamento e utilização de esgotos domésticos na agricultura. Campina Grande: UEPB, 2003. 135p.

Stevenson, J. F. Humus chemistry genesis: Composition, reactions. 2.ed. New York: John Wiley \& Sons, 1994. 496p.

Sumner, M. E. Sodic soils: new perspectives. Australian Journal of Soil Research, v.31, p.683-750, 1993.

Telles, D. d'A. Aspectos da utilização de corpos d'água que recebem esgoto sanitário na irrigação de culturas agrícolas In: Mancuso, P. C. S.; Santos, H. F. Esgoto sanitário: Coleta, transporte, tratamento e reúso agrícola. São Paulo: Edgard Blücher, 2003. p.461-483.

Trentin, C. V. Diagnóstico voltado ao planejamento do uso de águas residuárias para irrigação nos cinturões verdes da região metropolitana de Curitiba - PR. Curitiba: UFP, 2005. 129p. Dissertação Mestrado 